\title{
Tecnopolítica: da guerrilha armada à gestão da vida ${ }^{1}$
}

Tecnopolítica: de la guerrilla armada a la gestión de la vida

Technopolitics: from armed guerrilla to the management of life

\section{Domenico Uhng Hur}

Universidade Federal de Goiás, Goiânia, GO, Brasil

\section{Resumo}

Atualmente na América Latina há muitos países com governos de esquerda. No entanto as práticas políticas não seguem o socialismo, mas sim a lógica neoliberal. Este artigo tem como objetivo conhecer o discurso de militantes políticos brasileiros, ex-guerrilheiros da luta armada que viveram a transição da ditadura à democracia, para discutir essa aparente contradição. Com a análise das entrevistas propomos uma modalidade de discurso que denominamos de tecnopolítica. Este agenciamento discursivo caracteriza-se pela emergência de uma nova razão governamental, que se refere ao desenvolvimento de uma tecnologia da governabilidade, de saberes sobre a gestão, para guiar as práticas políticas. Dessa forma, os processos de saber e técnicos substituem as ideologias políticas na gestão do social e da vida.

Palavras-chave: Ditadura; Guerrilha; Governo; Psicologia Política.

\section{Resumen}

Hoy en día en Latinoamérica hay muchos países con gobiernos de izquierda. Pero las prácticas políticas no siguen el socialismo, sino la lógica neoliberal. Este artículo tiene como objetivo conocer el discurso de militantes políticos brasileños, exguerrilleros de la lucha armada que vivieron la transición de la dictadura hacia la democracia, para discutir esa aparente contradicción. Con el análisis de las entrevistas criamos una modalidad de discurso llamada de tecnopolítica. Este agenciamiento discursivo se caracteriza por la emergencia de una nueva razón gubernamental, que se refiere al desarrollo de una tecnología de la gobernabilidad, de saberes sobre la gestión, para guiar las prácticas políticas. Así, los procesos de saber y técnicos reemplazan las ideologías políticas en la gestión del social y de la vida.

Palabras clave: Dictadura; Guerrilla; Gobierno; Psicología Política. 


\begin{abstract}
Currently, in Latin America there are many countries with Left wing governments. However the political practices don't follow the socialism, but the neoliberal logic. This article intends to know the speech of Brazilian political actors, former-guerrilla fighters of armed struggle who lived the transition from dictatorship to democracy, to discuss this apparent contradiction. From the interviews analysis we propose a kind of discourse named by technopolitics. This discursive assemblage is characterized by the emergence of a new governmental reason, which refers to the development of a technology of governance, of knowing on the management, to guide the political practices. Thus, the knowledge and technical processes substitute the political ideologies in the management of the social and life.
\end{abstract} Keywords: Dictatorship; Guerrilla; Government; Political Psychology.

O terceiro milênio iniciou-se "vermelho" na América Latina. Muitos candidatos de partidos de esquerda, com plataformas políticas que têm referência no socialismo, acederam por via eleitoral ao poder executivo de uma série de países, trazendo até então um fato inédito para a história desse continente: o elevado número de governos de esquerda. Evo Morales na Bolívia, o tupamaro Pepe Mujica no Uruguai, o sandinista Daniel Ortega na Nicarágua, a ex-guerrilheira Dilma Rousseff no Brasil e mais uma porção de atores políticos de esquerda nos governos de países como Cuba, Venezuela, El Salvador, Equador, Guatemala, Paraguai, Peru, etc. Uma "onda vermelha" se propagou e tomou o poder de vários países latinoamericanos, fato que poderia deixar o "libertador" Simon Bolívar orgulhoso dos rumos políticos que esse continente tem tomado. Por esquerda política entende-se como o conceito de "movimentos e idéias endereçados ao projeto de transformação social em benefício das classes oprimidas e exploradas. Os diferentes graus, caminhos e formas dessa transformação social pluralizam a esquerda e fazem dela um espectro de cores e matizes" (Gorender, 1998, p.11). Compreende-se também os posicionamentos e práticas de grupos políticos compromissados com movimentos instituintes de transformação e crítica frente à lógica instituída e do Capital.

Todavia, algo diferente ocorreu. Talvez alguma coisa tenha dado "errado", pois a esquerda ao tomar o poder, não mudou o mundo como pretendia; tomar o poder do Estado não foi condição suficiente para realizar a transformação 
social propagada (Holloway, 2003) em seus planos de governo. Muito pelo contrário, por mais que alguns governos, como o da Bolívia, tenham operado mais transformações políticas que outros, constata-se um certo padrão, uma prática muito comprometida com planos econômicos neoliberais que resultou numa conexão entre ideologia de esquerda com economia de mercado. A articulação entre ideologia-organização política de esquerda com práticas neoliberais resulta num regime político híbrido que, na maioria dos casos, afirma-se mais capitalismo do que o socialismo defendido, transformando os projetos de governo de esquerda numa política pragmática, uma espécie de socialdemocracia latinoamericana (a qual é bem distinta da européia). Dessa forma, a esquerda não realizou o que vinha prometendo em períodos eleitorais, embora se reconheça que haja tímidos avanços para as populações pobres, através das políticas sociais adotadas.

Entretanto, pode-se dizer que se vive um período instituinte, em que não há o mesmo projeto de esquerda que se defendia nas décadas de 1960 e 1970 e tampouco um neoliberalismo que foi impresso de forma "selvagem" na década de 1990. Nessa nova configuração política latinoamericana, a esquerda não chegou ao poder autônoma e independente. Nas suas alianças pactuam com políticos e partidos de direita e o antigo ideal de soberania para as nações já não faz tanto sentido em tempos de Capitalismo Mundial Integrado - CMI (Deleuze \& Guattari, 1976), ou melhor, de Império (Hardt \& Negri, 2005), no qual as economias dos países estão em uma rede de entrelaçamento tão grande, que já se desvaneceram os antigos laços de imperialismo de um país sobre o outro. Ao invés das tradicionais relações de imperialismo há um Império transnacional em rede e descentralizado.

Devido a esse quadro, houve uma grande desilusão com a esquerda, e no Brasil, com o governo Lula e o Partido dos Trabalhadores - PT. Contudo, não queremos manter a mesma posição de setores da extrema esquerda, que se contentam em afirmar que o Governo Lula se vendeu, aburguesou-se (Michels, 1982), que o PT operou uma traição aos movimentos sociais, ou que é um mero continuísmo do Governo de Fernando Henrique Cardoso do PSDB - Partido da Social Democracia Brasileira. Supomos que o fenômeno seja mais complexo e digno de uma série de pesquisas e reflexões. Algumas hipóteses gerais podem ser pensadas, como: a impossibilidade de uma transformação do Estado a partir dele próprio (Deleuze, 1994), a intensificação do neoliberalismo, um aburguesamento das minorias dirigentes (Michels, 1982), o que acarreta um giro à direita nas práticas 
políticas dos atores sociais, entre outros fatores. Mas, enquanto um trabalho de Psicologia Social, além das dimensões políticas, econômicas e históricas, pretende-se pesquisar os fatores psicossociais que levaram a essa aparente 'não transformação' a partir dos discursos de um grupo que levou o projeto da Revolução socialista até o limite: os guerrilheiros do período do regime militar.

Consideramos que os guerrilheiros foram os atores sociais que percorreram o processo de transição mais radical da política contemporânea brasileira, pois aderiram à luta armada para combater a ditadura militar. Operaram uma ruptura com o Estado dominado pelos militares, numa luta em que puseram suas vidas em jogo contra o governo ditatorial e a favor da Revolução socialista; romperam com as leis instituídas reservadas à sociedade civil e entraram em outra lógica, em que a disputa política só poderia ser resolvida por relações de guerra e força.

$\mathrm{O}$ uso da força direta foi adotado antes pelos militares, quando operaram o Golpe de Estado em 1964, acabando com o governo do presidente eleito João Goulart, cassando os direitos políticos e aprisionando as principais lideranças de esquerda (Gaspari, 2002). As organizações e partidos opositores foram considerados ilegais e os que se mantiveram tornaram-se clandestinos (Mir, 1994). Então, abandonaram o projeto de conquista do poder do Estado via eleitoral e institucional e lançaram-se para a via militarista, da tomada do poder através da luta armada. Devido aos conflitos com as leis instituídas pelo regime militar, muitos militantes da guerrilha foram presos, torturados e assassinados nos cárceres dos aparelhos repressivos do Estado. Deste modo, a ruptura política e a luta contra o Estado não se deu apenas por um posicionamento romântico e idealista e sim por uma escolha teórica, prática e política que levou a uma grande implicação com a tarefa revolucionária. No Brasil, houve intensa repressão, em que foram assassinados cerca de quinhentos militantes de esquerda pelos aparelhos repressivos da ditadura militar (Gorender, 1998).

O projeto das organizações guerrilheiras foi o de combater a ditadura instituída e tomar o poder do Estado para acabar com a sociedade capitalista e instituir a comunista, tendo como referência teórico-política as teses marxista-leninistas (Reis Filho \& Sá, 2006). No projeto comunista, Lenin (1983), líder da Revolução Russa, defende a tomada de poder do Estado, pois só assim os trabalhadores poderiam se livrar da dominação e exploração da burguesia. Após sua conquista, o proletariado, como movimento social organizado, deve assumir o poder do Estado, tornando-se a 
classe dominante, e utiliza seu aparelho repressivo para “(...) arrancar, pouco a pouco, todo o capital à burguesia, para centralizar todos os instrumentos de produção nas mãos do Estado (...)” (Marx \& Engels citado por Lenin, 1983, p.30). Esse momento é denominado de ditadura revolucionária do proletariado, período intermediário da transição do capitalismo ao comunismo. Depois de combatida a burguesia, a classe operária deve quebrar e abandonar a máquina de Estado, que deixaria de ser necessária, pois não haveria mais contradição de classes sociais. Portanto, não se falaria mais em Estado, mas sim em Comuna, pois a propriedade seria de todos, comum a todos, comunal. Lenin defende: "Nosso objetivo final é a supressão do Estado, isto é, de toda violência organizada e sistemática, de toda coação sobre os homens em geral" (1983, p.101). Ou seja, para ele o advento do comunismo destruiria o Estado e a dominação de uns sobre outros, sendo a luta armada a estratégia para alcançar esse objetivo.

No período da ditadura militar brasileira, havia militantes que lutavam contra o Estado; hoje alguns desses mesmos militantes fazem parte dessa Instituição, em que não há mais ditadura, mas um Estado democrático neoliberal. Dessa forma entrevistamos quatro exguerrilheiros, que fazem parte ou não do governo, para conhecer seus discursos sobre suas práticas políticas e o imaginário da transformação social na conjuntura política do país. Colocamos algumas questões: Quais são os discursos da transição de uma prática política calcada na luta armada para outra no contexto do regime neoliberal? Como as práticas políticas no momento da guerrilha são reapresentadas hoje em dia a partir de suas experiências de vida? Qual o imaginário de transformação social que subsiste nos discursos apreendidos para a política atual nesse cenário neoliberal?

O objetivo desta pesquisa é conhecer o discurso de militantes políticos, ex-guerrilheiros, sobre a transição política da ditadura à democracia, para discutir a emergência de uma "nova" razão governamental, que denominamos de tecnopolítica. Para tanto, analisamos as entrevistas de dois ex-guerrilheiros denominados de Economista e Fotógrafo. Neste artigo não trabalhamos sobre as outras duas entrevistas realizadas, pois nelas não emergiu o agenciamento discursivo chamado de tecnopolítica.

Os dois entrevistados foram militantes da organização denominada Vanguarda Popular Revolucionária - VPR, grupo guerrilheiro comandado pelo “Capitão da Guerrilha" Carlos Lamarca (José \& Miranda, 1980). Fotógrafo começou sua militância política na Política 
Operária - POLOP, foi para a VPR e com a fusão dessa organização com o COLINA

- Comandos de Libertação Nacional surgiu a VAR-P - Vanguarda Armada Revolucionária - Palmares. Terminou sua participação na luta armada nessa Organização. Já Economista começou na VPR, foi para a VAR-P e retornou à nova VPR, quando um grupo de militantes decidiu cindir com a VAR-P (Lungaretti, 2004).

Realizamos com ambos os atores sociais uma entrevista semi-diretiva, no ano de 2008, fundamentada em dois tópicos principais: a militância política na guerrilha, e como analisa a conjuntura política atual do país. Para a análise da entrevista, operamos por análise de conteúdo (Bardin, 1977; Vázquez, 1997) com o intuito de discriminar e catalogar as diferentes unidades de registro. Em seguida passamos a codificá-las e agrupálas por analogia temática (Vázquez, 1997, p.4) para a constituição das categorias. Portanto, constituímos dois eixos gerais: a transição da luta armada à democracia e o imaginário da transformação social. A partir dos elementos emergentes elaboramos um tipo de agenciamento discursivo que pode ser explicativo do funcionamento das práticas e convicções políticas de nossos entrevistados: a tecnopolítica. Desenvolvemos tal noção a partir dos conteúdos emergentes das entrevistas e dos enunciados teóricos de Michel Foucault, Gilles Deleuze e Félix Guattari.

Vale ressaltar que entendemos o conceito de política conforme Bobbio, Mateucci e Pasquino (1991), que derivado do adjetivo polis:

\footnotetext{
significa tudo o que se refere à cidade e, conseqüentemente, o que é urbano, civil, público e até mesmo sociável e social,o termo Política se expandiu graças à influência da grande obra de Aristóteles, intitulada Política, que deve ser considerada como o primeiro tratado sobre a natureza, funções e divisões do Estado, e sobre as várias formas de Governo (...) (p.954).
}

A política então pode ser entendida como a prática social da polis, um espaço de discussão coletiva em que há um autogoverno e uma gestão do viver em coletivo, que gera seu próprio conjunto de regras (nomos). No espaço político, há um processo de debate e construção, no qual se decidem encaminhamentos para a gestão comum da vida e do território; compreendemos a política como a prática fundante e de gestão do Estado. 


\section{A prática política fundamentada no} saber: a tecnopolítica

Inúmeros relatos acerca das memórias da luta armada têm suas narrativas centradas em questões políticas e ideológicas adotadas na época, tais como as que estão nas variadas biografias, estudos e coletâneas publicadas (Salles, 2008; Reis Filho, 1990; Gorender, 1998, etc.). Esse fato não é de se estranhar, pois se trata de discursos de militantes e cientistas políticos. Entretanto, no discurso de Economista sobre sua trajetória política encontramos outro foco: sua reconstrução do passado, ao invés de ser marcada por questões político-ideológicas, foi majoritariamente estruturada a partir de um repertório de saberes técnicos. Para ele é a Economia que lhe dá os instrumentos "apropriados" para entender o mundo e a sociedade, sendo a disciplina em que investiu para construir sua atuação no social. Em sua fala, após descrever o terrível quadro de contradições sociais e concentração de renda no Brasil, afirma: “É claro, hoje vejo isso com esse tipo de análise, porque a Economia te dá esse nível de compreensão" (Economista, 233-234²), ou seja, sua análise social deriva-se antes dos conhecimentos que a Economia lhe proporcionou, ao invés da tradicional análise político-ideológica derivada dos repertórios dos partidos e organizações políticas sobre a conjuntura social. Da mesma forma ele se refere ao seu processo de politização, que também é tributário do acúmulo de saberes, mais do que de formações políticas "clássicas": "Tem visões, digamos, para você empreender determinadas atividades políticas em que você, claro, usa um conhecimento da Ciência, da pesquisa social, de mecanismos econômicos etc., até entender como funcionam os processos" (Economista, 242-245). Seu discurso referenciado nos saberes da Economia para a gestão política é tão intenso, que, para ele, supera a clássica discussão pautada nas ideologias do capitalismo versus comunismo:

\footnotetext{
Uma coisa é eu estudar Economia, outra coisa é a rentabilização na Europa, com o sistema da social-democracia e entender que dá perfeitamente para ter um lugar ao Sol para cada um. E que não é questão de capitalismo ou de comunismo, mas uma questão de decência humana e de uma organização adequada dos processos" (Economista, 102-105).
}

Então fica explícito para Economista que uma gestão mais eficaz dos processos sociais pode dar conta dos problemas relacionados às contradições sociais, independente das ideologias capitalista e socialista-comunista. A socialdemocracia européia é considerada como um regime com eficácia social, que pode 
superar o embate ideológico entre capitalismo e comunismo, o debate político que marcou o século XIX, todo o século $\mathrm{XX}$ e que parece pouco marcar o século XXI. A questão social pode ser resolvida com mecanismos mais organizados de gestão, adicionado a uma moral de "decência humana" e "dignidade", termos muito recorrentes em sua fala. Consideramos então que o discurso do Economista somado aos seus valores pessoais funda-se numa tecnologia da gestão da política e do social.

Tal discurso também aparece na fala do Fotógrafo, como por exemplo, quando este critica o PT no poder do Estado. Uma de suas críticas é de que muitos dos quadros políticos do partido carecem de formação teórica e técnica para gerir a máquina estatal e social, formação que considera imprescindível para o fazer político atual: “(...) o PT não teria quadros para completar tudo, não tem gente nem preparada; tem gente com pouca formação para o cargo onde foi colocada" (Fotógrafo, 672-674). Em seu discurso é fundamental que os políticos tenham uma boa formação técnica para poder gerir a maquinaria estatal, pressuposto que Fotógrafo considera ser difícil de ser encontrado no PT da atualidade.

Dessa forma, a partir das entrevistas constatamos um tipo de agenciamento discursivo que se distingue do modo tradicional de fazer política, que não corresponde mais à lógica de possuir determinados repertórios ideológicos para governar e efetuar as transformações sociais. Essa modalidade política não se refere ao movimento de fixação nos estratos de poder, nem mais à primazia de ocupar determinados cargos e posições na estrutura governamental. Nesse agenciamento, ao invés da função estratégica de ocupar lugares institucionais para realizar práticas políticas, focaliza-se mais no desenvolvimento de saberes e técnicas que fomentem uma gestão mais eficaz do social. Enfim, há todo um desenvolvimento de uma tecnologia da política, de uma tecnologia de governabilidade, que conforma outra lógica de processos políticos frente às práticas políticas tradicionais, que chamamos aqui de tecnopolítica. $\mathrm{O}$ discurso tecnopolítico aparece como justificação do trânsito da uma prática política da luta armada para a democrática e está presente em toda fala de Economista e em alguns trechos da fala de Fotógrafo. Mas tomando o relato de Fotógrafo como um todo, diferente de Economista, além de abordar a necessidade de formação técnica, também aborda a importância da formação política.

O cerne da tecnopolítica é a competência desenvolvida nos saberes de cada campo. Consideramos que a 
emergência desse agenciamento só foi possível mediante o triunfo da axiomática do capital como funcionamento do social e para a produção subjetiva, o que consolidou a primazia do neoliberalismo como sistema político-econômico. Tal processo gera uma maior maleabilidade das posições e das estruturas, em que as instituições tiveram que se adaptar e modular-se por tal axiomática, tornando assim as fronteiras estatais mais fluidas, pois, a axiomática do capital opera por um duplo movimento: de descodificação dos fluxos sociais anteriormente codificados, e de axiomatização desses fluxos conforme sua lógica (Deleuze \& Guattari, 1976). Portanto, tal funcionamento torna as estruturas mais móveis, tira a determinância dos estratos, mas não chega a desterritorializá-los totalmente, pois a axiomática do capital ainda é dependente do estrato estatal, tendo em vista que não rompe os limites institucionais, mas sim maleabiliza-os, constituindo-se assim um Estado neoliberal (Deleuze \& Guattari, 1997). Então, não só o aparelho estatal é importante para gerar governabilidade, mas principalmente os dispositivos de saber que instrumentalizam e referenciam os governantes a tomar suas decisões políticas e a lidar com os fluxos do capitalismo (Foucault, 2008b).

Esta reflexão também é referenciada nas postulações de Foucault
(1979; 2008b) sobre uma lógica da governamentalidade, a qual desloca o foco da questão de quem ocupa ou não o estrato do Estado, para a questão de como os conhecimentos desenvolvidos e aplicados por técnicos e pensadores sociais geram governabilidade, tanto política, como das condutas. Considerando-se que hoje em dia todo plano de governo refere-se prioritariamente à gestão dos fluxos financeiros, à maquinação sobre o axioma do capital, compreende-se que o desenvolvimento de uma tecnologia de gestão do governo, da vida e dos fluxos econômicos, a tecnopolítica, ganhe força mediante os posicionamentos ideológicos de determinado grupo político.

Deste modo, entendemos a tecnopolítica como o agenciamento político calcado nos conhecimentos e dispositivos elaborados pelos coletivos e instituições sociais para a melhor gestão da economia, do governo, da vida e da sociedade. Portanto, não há mais a primazia das tradicionais formas de poder das instituições sociais na política, mas sim dos conhecimentos desenvolvidos pelas instituições e pelos coletivos sociais, seja disciplinares e de controle (Foucault, 2008a), que possam promover uma gestão da vida mais eficaz, independente das ideologias políticas que determinado governo possa adotar. Então ela é desenvolvida a partir da racionalização dos 
processos sociais, da gestão social e, principalmente, da gestão dos fluxos financeiros, axiomatizados pelo Capital (Deleuze, 2005). Não importa mais uma prática política guiada por determinados repertórios ideológicos, mas sim uma política "pragmática" que resulte no desenvolvimento das melhores ferramentas que constituam o conjunto da tecnologia social e que são operadas pelos tecnólogos sociais, pelos tecnólogos da política, pelos tecnopolíticos. Dessa forma, uma decisão política não será apenas guiada por valores, questões éticas e de plataforma política, mas principalmente pelos índices de eficácia social que a tecnologia da política tenha mensurado, medido e previsto. Portanto, mais que a opinião de assessores, ideólogos, ou de figuras políticas tradicionais, o que toma maior relevo é o resultado de determinada medida estatística, a avaliação do impacto social de determinada política pública, o resultado de determinado survey. Enfim, a tecnopolítica se funda em todo um cabedal de conhecimentos e dispositivos técnicos que criam fórmulas e axiomas para que as ações da gestão social possam ser mais eficazes. Não só anátomo-política, biopolítica (Foucault, 2008b) e noopolítica (Lazzarato, 2006), mas, sobretudo, em tempos de neoliberalismo, a tecnopolítica escora-se fundamentalmente numa "ecônomo-política", no cálculo e na gestão dos fluxos financeiros e sociais, ou seja, ao invés de seguir uma lógica do verbo "ser", característica da política tradicional, na tecnopolítica temos a primazia do verbo "saber". A tecnopolítica então pode ser pensada como o sistema de gestão da política que não fica restrito aos mecanismos disciplinares e biopolíticos que Foucault (2008a) postulava, mas passa a ser também a razão governamental do próprio Estado, em que toda maquinaria estatal passa a funcionar a partir dessa lógica, via saberes mediados pela axiomática do capital. Pode-se afirmar assim que a tecnopolítica é o apogeu do biopoder e da governamentalidade.

\section{Transição do período da luta armada à}

\section{democracia}

A tecnopolítica aborda de forma distinta as narrativas tradicionais presentes na literatura sobre o trânsito da luta armada à democracia. Ao invés de enaltecer a positividade dos momentos históricos vividos, dos estratos ocupados, aborda como tais experiências contribuíram para a aquisição de saberes para a compreensão do social. Então, a adesão à luta armada no discurso tecnopolítico se justifica pelo acúmulo de saber em relação a uma situação socialmente injusta, de opressão e desigualdade que deveria ser modificada. $\mathrm{O}$ relato de Economista se escora muito 
mais em análises a partir de conhecimentos da Economia, conforme sua percepção e valores, do que em teorizações das referências políticas da esquerda. Economista descreve assim o quadro de desigualdade e injustiça social do Brasil:

O choque que foi, digamos, relativamente à Europa é muito grande. Um país com desigualdades tão dramáticas, com uma classe dirigente extremamente arrogante e profundamente desvinculada dos interesses da nação como um todo; ligada às atividades agro-exportadoras e a interesses internacionais, mas com pouquíssima compreensão das necessidades do desenvolvimento no seu conjunto (...) o choque da imensa pobreza frente a uma riqueza foi grosseiro. É, inclusive, [uma classe dirigente] que tenta se impor, se escancarar de maneira ostensiva. Isso gera choques que não precisam de nenhuma leitura de Marx, nem de Che Guevara, nem nada do gênero, simplesmente são coisas que pegam pela imoralidade que representam, imoralidade que continua rigorosamente intacta hoje nas lojas como Daslu, nas distâncias entre Alphaville e Alfavela, como se chama os bairros na região. Interessa a prosperidade inababesca e deixar dezenas de milhões de pessoas passando fome. Isso não é decência política para lado nenhum, não é questão de ideologias, é de um mínimo de decência humana, que para mim era a raiz da minha atitude (Economista, 29-42).

De acordo com o fragmento de sua fala, o que motivou sua participação política guerrilheira foi a compreensão da enorme contradição social entre distintos grupos no Brasil, o que violentava seus valores e princípios. Nota-se que nessa modalidade de discurso a compreensão dos fatores toma determinância frente às ideologias, por exemplo, ao se referir ao "choque" sentido em relação à pobreza e às contradições sociais, que aparecem como fatos concretos que prescindem de qualquer leitura das referências teóricopolíticas apoiadas em Marx ou Che Guevara, marcos da esquerda revolucionária, para serem compreendidos. Em seu discurso, a todo momento, busca descolar-se das crenças e valores instituídos pelas organizações políticas. Defende-se o entendimento do mundo a partir da produção de análises diretas sobre o vivido e não através da reprodução de ideologias instituídas, tal como do projeto socialista-comunista. Portanto, o discurso tecnopolítico funda-se nos saberes e busca situar-se além das ideologias e dogmas de esquerda.

Haja vista que é um discurso que procura descolar-se das ideologias, encontramos vários trechos na fala de Economista que operam dessa forma, num rechaço às ideologias, às etiquetas $\mathrm{e}$ estereótipos, seja relacionados à sua ação política ou de outros atores sociais, em que sempre objetiva colocar a compreensão do 
social e os valores éticos como fundamentos da ação política:

Esse duplo movimento, minha tomada de consciência, os estudos de um lado; e do outro, a formação da ditadura e a ruptura de toda uma visão antiga e meio fossilizada de um comunismo, partido leninista e todas essas coisas que a gente não sentia como nenhuma alternativa realmente... A gente era contra o sistema, mas na época qualquer pessoa que fosse contra o sistema significava que era, que tinha que ir para Moscou. Enfim, querer modernizar a situação do seu país significava que você era contra o país. Então, 'Ame-o ou deixe-o', ou seja, aceite a situação imposta pelos grupos mais privilegiados ou então você está destituído da brasilidade de certa maneira (Economista, 121-129).

Era muito fácil na época jogar qualquer interesse por um pouco mais de decência social como sendo comunismo. Então, de certa maneira, as mesmas pessoas que geraram tragédias familiares, de comunidades, de grande parte da população, podiam encher a boca dizendo 'Estamos fazendo isso em nome da defesa da democracia'. A própria ditadura em defesa da democracia. É preciso ter uma cara razoavelmente sórdida para defender esse tipo de posicionamento (Economista, 64-69).

Economista atribui aos grupos dominantes um movimento de criar estereótipos negativos em relação aos que lutavam por "decência social" e que eram "contra o sistema", como sendo comunistas. Então, para ele, os grupos que implantaram a ditadura no Brasil queriam justificar a tomada de poder do Estado com o discurso da "defesa da democracia", colocando os opositores a essa atitude como sendo comunistas. Entretanto Economista diz que, já no passado, fazia a crítica da visão comunista-leninista que considerava "fossilizada" e que não era uma alternativa eficaz contra o sistema instituído. Assim, esse discurso denuncia como qualquer grupo de opositores ao regime ditatorial era colocado, homogeneizado, sob a etiqueta do comunismo e como um inimigo da nação, como no marcante lema do Estado da ditadura: "Brasil, Ame-o ou Deixe-o".

O discurso tecnopolítico reafirma seu distanciamento em relação às ideologias, pois sua lógica de funcionamento e justificação dos fatos pauta-se no "saber" e não no "ser". Para justificar essa separação, analisa a função e gênese desse movimento de "etiquetação" perpetrado pelos grupos dominantes para depreciar qualquer movimento social, em que a mídia ocupa papel estratégico:

No Brasil, a conivência dos grandes grupos da mídia, dos que estão aí, os Marinhos, os Mesquitas, etc., que se demonizou qualquer iniciativa de justiça social, 
sempre atribuindo desígnios ideológicos, misteriosos. No conjunto não era nada disso, a maior parte das pessoas que conheci, mesmo no processo da luta armada, era gente que simplesmente estava indignada com os processos. Muitos iriam ler Marx e outros depois, tentando entender... Gerava uma admiração por Fidel Castro, Che Guevara etc., porque ali tinham mudado o sistema. É natural, você busca pontos de referência, quando os pontos de referência que te servem são essencialmente, extremamente, limitados ou simplesmente negativos. Esse é um país que ainda recentemente tinha uma presidência do Congresso, que era gente que; pega Inocêncio, Antonio Carlos Magalhães, pega Paulo Maluf no governo de São Paulo. Estamos falando de um nível de pessoas que são abaixo da decência elementar de qualquer pessoa modesta trabalhadora decente que há nesse país (Economista, 205-216).

Nesse fragmento Economista explica que a "etiquetação" dos movimentos contra a ditadura como sendo comunistas correspondia a uma tática de criação de culpados, de bode-expiatórios (Pichon-Rivière, 1986) feita pelo regime militar contra seus opositores. E volta a redargüir que a vinculação ao comunismo não foi um a priori dos movimentos, em muitos casos veio depois, na busca de referências políticas melhores do que as que estavam no Estado, seja o Estado militar das décadas de 1960 e 1970 ou o Estado democrático da atualidade, no qual há um montante de políticos envolvidos em uma série de casos de corrupção. Então a adesão às idéias de Marx, Fidel Castro e Che Guevara vinha mais pelo desejo de transformar o estado de coisas do que o compartilhamento anterior à ideologia comunista. Na sua crítica aos movimentos de etiquetação recorre a outros casos históricos de luta contra a opressão como exemplos que recebiam o estereótipo de terrorista (Economista, 254-268). Cita os estereótipos pejorativos dados a uma série de movimentos sociais, como a ação libertadora de Mandela e Gandhi como terrorismo, a ação igualitária da feminista como fanatismo, e finalmente a atuação dos guerrilheiros, ao menos a sua, como comunismo. Assim, a operação tecnopolítica funda-se em saberes sobre o social e a política, e não sobre ideologias e estereótipos constituídos.

Este discurso não exalta a ação da luta armada, muito pelo contrário, assume olhar bastante crítico a algumas atuações, como a crítica a uma visão considerada ingênua e a uma precariedade de repertório teórico para interpretar os acontecimentos sociais:

\footnotetext{
Nós tínhamos um denominador comum de ser contra essa ditadura, mas as pessoas vinham de origem extremamente diferente. A gente, por exemplo, o gigantesco êxodo rural, a expulsão da população do campo que se deu, foi pouco estudado durante o
} 
regime militar, que formou essas periferias explosivas aqui, no Rio e em toda a parte. Expulsar a gente do campo sem que pudessem lutar na cidade, essa era uma base para um processo de conscientização do regime muito forte. O pessoal lia livro do Karl Marx e dizia 'Não, isso aqui é lumpen-proletariado'. $\mathrm{Na}$ época, que se chamava marginalização econômica, hoje se chama de exclusão. E essas classes excluídas são uma base muito forte, digamos, para se mobilizar contra o regime. Na realidade, havia pouca cultura política de base, pouca maturidade no conjunto do movimento... Tinha muita indignação, muito idealismo (Economista, 397-406).

A visão ingênua nossa, porque a gente subestimava o poder político do processo. Era assim, a gente se armando, achando que era um movimento capaz de enfrentar o regime. Acho que era muito ingênuo, mas precisa ver que, na época, você tinha lutas armadas espalhadas por todo $\mathrm{o}$ planeta; mesmo os movimentos de libertação na África, as lutas no Vietnã, os Black Panthers nos Estados Unidos, havia uma indignação ao conjunto de sistemas que estavam aí, muito forte (Economista, 322-327).

E depois que você perdeu, se eu tivesse lido a experiência da resistência francesa na guerra, na segunda guerra mundial com os nazistas, pelo que eu li depois no exílio, se eu tivesse lido antes, a gente teria evitado muitas mortes. Fizemos muitos erros que a história realmente já tinha cometido e nós não sabíamos... Se a esquerda brasileira era ingênua teoricamente, era mesmo... Não tem solução para nada na situação atual, a esquerda mundial é outro problema (Fotógrafo, 351-356).

Nesse agenciamento há uma autocrítica da própria atuação como sendo idealista, com pouca base teórico-política e ingênua, sendo uma atuação que subestimou o poder político-militar da ditadura e conseqüentemente superestimou o próprio poder. Critica a falta de uma maior teorização dos processos e uma fixação aos "dogmas" marxista-leninistas. Tanto que no caso relatado por Economista impossibilitou-se uma melhor leitura dos movimentos de migração da população rural, etiquetando-os equivocadamente de "lumpen-proletariado", o que decorreu para a sua não arregimentação às fileiras das organizações de guerrilha contra a ditadura, diminuindo assim sua potência de ação. Por outro lado, ao mesmo tempo em que afirma ter sido uma atuação com uma visão ingênua, ela é justificada devido a influências de movimentos insurgentes exitosos no mundo, como a resistência dos vietnamitas contra os norteamericanos, os movimentos de libertação na África e os movimentos raciais, que atuaram como referência positiva para tentar a transformação do quadro negativo do Brasil. Já Fotógrafo afirma que a ingenuidade e pouca formação teórica 
marcavam a esquerda do passado, como a do presente, que não tem soluções para os problemas atuais.

Economista (327-331) apenas enaltece o que a luta armada tinha de organização nas ações, não relatando os equívocos realizados. Selecionar e falar sobre as ações bem montadas é querer expressar o saber que se tinha em sua organização; expressa o saber tecnopolítico da guerrilha. Tal seleção é interessante, pois a VPR igualmente realizou ações armadas bastante equivocadas (Gorender, 1998; Mir, 1994). Economista (339-342) também justifica a adesão à luta armada pela legitimação social que tinha dentro da intelectualidade brasileira politizada, ou seja, os intelectuais têm um saber que legitimou a participação na guerrilha armada.

Economista, após ser preso e ser um dos libertados no caso do seqüestro do embaixador alemão Ehrenfried von Holleben, teve que sair do país. No exterior resolveu se afastar do movimento dos exilados brasileiros por considerá-los grupos fechados em si (Economista, 361). Investiu em sua formação acadêmica e técnica, ao cursar mestrado e doutorado na Europa e trabalhar com Economia e docência em diferentes países, ou seja, investindo mais em sua formação teóricotécnica. Tanto que sua participação no PT, quando retornou ao Brasil com a redemocratização do país, não foi em assuntos de coordenação política, mas em assuntos técnicos, a partir de sua formação tecnopolítica, visto que participou da comissão de políticas internacionais do partido (Economista, 515) e posteriormente realizou uma série de avaliações de políticas públicas, como será citado no próximo tópico.

Então a tecnopolítica vê a sua participação política mais pela função técnica, do que pela função política, mais em contribuições pela via do saber e tecnológica, do que na participação e na militância orgânica do cotidiano do estrato partidário. Por exemplo, Economista resolveu participar de uma comissão em que seus conhecimentos técnicos seriam diretamente contributivos. Da mesma forma Fotógrafo, na sua participação no PT, após o exílio, também se referiu à sua militância no partido, eminentemente através do seu repertório técnico como comunicador social (jornalista-fotógrafo):

\footnotetext{
Fiz duas campanhas para o Zé Dirceu, três campanhas para o Rui Falcão; trabalhava em campanhas. Aí quando me enchi o saco das campanhas também: 'Não me peçam mais para fazer discussão de campanha, marketing político'. Porque eles botam um bando de gente para discutir marketing político, para fazer campanha de deputado, que é a coisa mais elementar que tem. Para que ficar discutindo com um bando que
} 
não tem idéia nenhuma?! Vou ficar lá duas, três horas. Não é para assumir o que proponho, mas para mim é mais fácil eu fazer uma lista daquilo que eu proponho, daquilo que eu acho e está tudo pronto. ' $\mathrm{E}$ discutam sem minha presença'. Porque eu ficar discutindo coisas com pessoas que não entendem... Eu não vou ficar discutindo economês com um economista, coisas que não entendo de economia, eu não vou ficar discutindo. Tomar decisão política na área de economia, se eu não entendo? Eu não vou ficar enchendo o saco (Fotógrafo, 734-745).

Nesse fragmento, Fotógrafo aborda claramente sua função técnica na militância do PT, em que sua atuação política era a de trabalhar em campanhas eleitorais, fazendo marketing político, visto que tinha conhecimentos de comunicação social. Fotógrafo relata que quando retornou do exílio se ligou ao PT via núcleos profissionais, de jornalismo, e começou a se aborrecer ao ter que discutir as tarefas de marketing político com quem não entendia nada de marketing e que não tinha o repertório de conhecimento técnico para fazer tal discussão. Disse que não discutiria Economia com um economista, por não ter conhecimentos suficientes dessa disciplina; não se meteria em campo de conhecimento que não fosse de seu domínio. Quando teve que participar dos núcleos regionais (Fotógrafo, 717-719), em discussões mais políticas e menos técnicas, aborreceu-se mais ainda, o que motivou seu desligamento do partido. Percebe-se nesse discurso, tecnopolítico, que há a primazia do conhecimento técnico em relação ao fazer político, em que é um conhecimento que não precisa passar por um debate político para ser efetivado, pois já se legitima em si, em sua disciplina de saber, havendo assim o esvaziamento do espaço do político. Então a prática política na luta armada é rememorada a partir dos traços que têm a ver com uma atuação que esteja mediada pelo saber e não pelas ideologias e opiniões de determinado coletivo social. Um saber que é decisivo na continuidade ou não da participação política, em que a participação deixa de ser guiada pela fixação às crenças instituídas, e sim através da composição a partir da conjunção dos saberes. Na transição à democracia, nos dois casos investigados relativos ao agenciamento tecnopolítico, houve certo afastamento da política institucional, em que Economista preferiu investir em sua carreira acadêmica e Fotógrafo se aborreceu por ter que debater com pessoas com pouca formação e com a burocracia partidária.

\section{O imaginário de transformação social}

O imaginário da transformação social na tecnopolítica é decorrência direta do seu funcionamento e dos seus traços, 
fundando-se num acúmulo de conhecimento técnico sobre o social, que pode tornar mais eficaz a governabilidade e a gestão da política e da sociedade. Então mais do que ideologias e utopias, a tecnopolítica busca trazer números, resultados e indicadores para mensurar, prever e planejar a transformação social.

Economista relata que realizou avaliações de projetos de políticas públicas do Governo Lula, afirmando que tais práticas estão mudando o país e a crônica contradição social existente, no entanto de forma ainda aquém do esperado (Economista, 113-114). Contudo, no decorrer da entrevista, passa a enaltecer os resultados do Governo petista, diferentemente do caráter tímido que atribuiu no início:

Ele organiza uma convergência que é o Bolsa Família que atinge quarenta e oito milhões de pessoas, o aumento em cerca de trinta por cento da capacidade de compra do salário mínimo, atinge cerca de vinte e cinco milhões de pessoas. O salário mínimo é o indexador das aposentadorias, então a tragédia que eram os velhinhos miseráveis, é uma mudança profunda. Para o andar de baixo, um pouquinho de dinheiro a mais é uma imensa diferença. Quando você tem pouco dinheiro, um pouquinho é muito significativo. Você tem o Pronaf que atinge cerca de três milhões de famílias, uma multidão de pessoas, que saiu de dois e meio bilhões de reais para doze e meio bilhões de reais. Você tem o movimento de território de cidadania, são onze ponto três bilhões para novecentos e cinquienta e oito municípios, agora vai dobrar em 2009. Você tem o Prouni que está colocando um mundo de gente da área pobre que nunca teria acesso a Universidade, está colocando na Universidade. Você tem as cotas (...) você vai juntando esses diversos elementos, nós tivemos o aumento na primeira gestão do Lula de oito ponto sete milhões de empregos, três em cada cinco empregos formais. Tudo isso aí - como faço profissionalmente e como fazia nas Nações Unidas avaliação de políticas públicas - já apresentava no início de 2007, já estavam lá os resultados (Economista, 435-454).

Então a avaliação tecnopolítica da esquerda no poder do Estado não obedece aos parâmetros de fidelidade ideológica aos dogmas teóricos da esquerda e sim aos resultados obtidos, ou seja, preza-se não uma política ideológica e sim uma política de resultados, uma política pragmática. E para Economista os resultados aparecem na medida em que o governo diminui as terríveis disparidades entre os distintos grupos sociais do Brasil. No trecho abaixo explica porque tais políticas funcionam e têm eficácia social:

$\mathrm{Eu}$ analisei cento e quarenta e nove principais projetos de inclusão social do Governo, e funciona. Não funciona pela genialidade do Lula, mas pela sua base política, porque ele puxou, não a velha 
guarda política, mas puxou gente de movimentos sociais que entende tudo de organização político-social. E puderam manter esse processo. A política funciona e como funciona! Estão aí os resultados, GV, IPEA, PNAD, etc. Isso me dá imensa esperança. E o curioso é que não foi como a direita sempre pensou, os privilegiados, que qualquer política para pobres seria contra eles; eles também estão melhorando e está melhorando mais rápido a base. E mais, se você olha os programas de Governo da América Latina, estão todos centrados em torno da Economia (Economista, 460-468).

Dessa forma, ao citar tais dados resultantes de avaliações de políticas públicas, Economista entende que o Governo Lula está promovendo um processo de transformação social no país. No início disse que era um processo tímido, mas posteriormente se exaltou com os números e afirmou grande otimismo com os processos de transformação fomentados pelas políticas de governo do PT. Vale ressaltar que a importância atribuída à participação de membros de movimentos sociais nos projetos não se dá pela lógica da representatividade dos movimentos no governo, mas sim pelo saber acumulado sobre organização político-social que eles têm, ou seja, se dá pelo critério tecnopolítico.

Além das práticas de governo com bons resultados, a tecnopolítica também imagina a transformação social através do acúmulo de conhecimento que a população em geral adquire com a difusão dos conhecimentos desenvolvidos nas diferentes disciplinas do saber, seja por meio da internet, ou outras mídias, como a imprensa alternativa:

O que tem agora de relativamente novo é que cada vez mais a gente entende como se dão os processos, porque há a internet, uma série de imprensa alternativa, com um nível muito mais amplo de formação das pessoas (...) hoje você tem milhares de pessoas no mundo que estão gerando consciência à população (...) muita gente está começando a ver uma necessidade desses movimentos, como o Fórum Social Mundial, etc. Acho que uma questão histórica, no sentido de mais democracia, de mais liberdade, de menos desigualdade, de menos destruição do planeta, são posições muito mais amplas do que antigamente se definia como esquerda; e claramente contrárias ao quisto de resistência da direita que continua a dilapidar o planeta, concentrar renda e manter esse sistema de poder que desagrega a democracia (Economista, 288304).

Hoje a coisa está mudando (...) Na base da sociedade você tem gente que não vê TV de maneira besta só, mas interpreta as coisas, jovens que já passaram na escola. Você tem gente que sabe que pode se viver de outra maneira, gente que sabe e que tem consciência de seus direitos, então essa coisa está amadurecendo. Não se pode 
manter para toda vida, esse tipo de Casa Grande Senzala modernizada que nós somos (...) Os desafios estão aí, mas acho que hoje, pela primeira vez, as coisas estão caminhando (...) o desafio é civilizatório. E hoje felizmente, tem uma quantidade de gente que está consciente disso, não só na esquerda (Economista, 471-492).

O imaginário de transformação social via tecnopolítica se dá, além das práticas de governo serem referenciadas pelas disciplinas de saber, a partir da constituição de uma população mais esclarecida, com maior acesso aos conhecimentos e dos mecanismos sociais e de uma maior apropriação do processo de governança e gestão da vida. A revolução social vai além da ideologia de esquerda e se dá pela sensibilização e compreensão do coletivo sobre as vicissitudes vividas, em que não só a esquerda se mobiliza, mas também pessoas que diretamente estão envolvidas com o mercado financeiro e outras organizações (Economista, 493$500)$.

Portanto, compreendemos que na tecnopolítica há uma especialização do saber e fazer técnicos que muitas vezes pode até dispensar a discussão política. Tal repertório de conhecimentos e técnicas se legitima por si só e constrói regimes de verdade que vão além do debate político, não precisando de uma apreciação coletiva para ser aprovado ou não. O que importa é o discurso competente (Chauí, 2001), o discurso do especialista, seus regimes de verdade para a governabilidade do social e das condutas; seja do especialista em comunicação social que faz as campanhas políticas, ou do economista que faz um projeto econômico para algum governo: na tecnopolítica há o primado do fator técnico sobre o fator político. Será que a tecnopolítica é o agenciamento político que marcará o século XXI, em detrimento dos "antigos" embates ideológicos e políticos? Chegamos à morte do embate capitalismo versus comunismo? Ao período do fim das ideologias na gestão da maquinaria estatal? Ao período em que o "rei" não deve mais ser o filósofo, como Platão sustentava, mas sim o tecnopolítico?

\section{Considerações finais: o futuro é a}

tecnopolítica?

A partir das entrevistas de Economista e Fotógrafo e de nosso referencial teórico elaboramos $\mathrm{o}$ agenciamento discursivo que chamamos de tecnopolítica. Esse agenciamento não opera na lógica da política tradicional, a partir de ideologias, posicionamentos políticos fixos e na tentativa da tomada do poder, mas sim na primazia dos saberes técnicos desenvolvidos para a gestão da política e da vida. Na tecnopolítica, a tecnologia da política assume 
determinância sobre a gestão da sociedade e da vida, em relação aos tradicionais mecanismos de deliberação política coletiva e ideologias.

Do ponto de vista geopolítico, consideramos que com o fim do bloco comunista no desfecho do século $\mathrm{XX}$ e o triunfo do capitalismo, houve uma desterritorialização em relação às ideologias no fazer político. Então, mais que a execução de projetos ideológicos, o que entrou na agenda dos governos, acompanhando os fluxos do Capital, foi a sofisticação dos mecanismos de gestão e de administração, dos saberes e técnicas disciplinares e de controle. Dessa forma, para grande parte dos governos o que se torna mais importante é o desenvolvimento de saberes técnicos para a gestão da vida e da sociedade que capitalize mais saberes e traga mais resultados “concretos". Então é necessário um desenvolvimento de saberes sobre a política e a vida que prescinda das ideologias, pois a tecnopolítica, calcada no saber, busca ser anti-ideológica, ou então, no máximo, porta a ideologia do saber técnico, do saber do especialista. A tecnopolítica funda-se no saber e não no ser. Não surpreende o surgimento do agenciamento tecnopolítico nos relatos dos ex-guerrilheiros, pois muitos tinham alto grau de formação acadêmica (Ridenti, 1993), o qual obviamente foi utilizado para analisar os conflitos contra a ditadura militar e nortear seus pensamentos e práticas políticas.

Atualmente, na política institucional, constatamos que já há uma primazia da tecnopolítica. Reflexões e discursos como de Economista a cada dia ganham mais espaço no cenário político. Conseqüentemente, o imaginário da transformação social da tecnopolítica se encarna no projeto de criar saberes e mecanismos, dispositivos tecnopolíticos, mais eficazes de administração da vida e dos coletivos, e numa melhor formação dos técnicos da política e também da população. Mesmo com a permanência de lideranças carismáticas na política (Dorna, 2007) consideramos que essa é a tendência no perfil dos planos de governo na América Latina, em que passa a ser mais valorizado o político que tem um perfil de bom gestor, bom administrador, do que um político que tenha sólida formação histórico-político-ideológica. Por isso que a esquerda latinoamericana não promove a transformação socialista sustentada no passado e assume como prática uma política pragmática. Tanto que vemos a predileção de governantes em colocar pessoas com um perfil técnico em cargos políticos, ao invés de um histórico como político. Compreendemos que a tecnopolítica está articulada pela axiomática do Capital, reproduzindo e fortalecendo essa forma político- 
econômica. A questão que se coloca é: será que os saberes da tecnopolítica um dia prescindirão dessa axiomática?

\section{Notas}

1 Pesquisa financiada pelo $\mathrm{CNPq}$ e pela CAPES.

${ }^{2}$ Os números referem-se às linhas em que se localiza a citação na entrevista integral.

\section{Referências}

Bardin, L. (1977). Análise de conteúdo. Lisboa: Edições 70.

Bobbio, N., Mateucci, N. \& Pasquino, G. (orgs) (1991). Dicionário de Política. Brasília: UnB.

Chauí, M. (2001). Cultura e democracia. São Paulo: Cortez, $9^{\circ}$ ed.

Deleuze, G. (1994). O Abecedário de Deleuze. Documentário.

Deleuze, G. (2005). Derrames: Entre el capitalismo y la esquizofrenia. Buenos Aires: Cactus.

Deleuze, G. \& Guattari, F. (1976). O AntiÉdipo. Rio de Janeiro: Imago.

Deleuze, G \& Guattari, F. (1997). Mil Platôs: Capitalismo e Esquizofrenia, Vol. 5. São Paulo: 34.

Dorna, A. (2007). A Psicologia Política, o líder carismático e a personalidade democrática. Lisboa: Livros Horizonte.

Foucault, M. (1979). Microfísica do Poder. Rio de Janeiro: Graal.

Foucault, M. (2008a). Segurança, Território, População: Curso dado no Collège de France (1977-1978). São Paulo: Martins Fontes.

Foucault, M. (2008b). Nascimento da Biopolítica: Curso dado no Collège de France (1978-1979). São Paulo: Martins Fontes.

Gaspari, E. (2002). A ditadura envergonhada. São Paulo: Cia das Letras.

Gorender, J. (1998). Combate nas Trevas. São Paulo: Ática. $5^{\circ}$ Ed.

Hardt, M. \& Negri, A. (2005). Imperio. Barcelona: Paidós, Surcos.

Holloway, J. (2003). Mudar o mundo sem tomar o poder. São Paulo: Viramundo.

José, E. \& Miranda, O. (1980). Lamarca, o capitão da guerrilha. São Paulo: Global Editora.

Lazzarato, M. (2006). Políticas del acontecimiento. Buenos Aires, Argentina: Tinta Limón.

Lenin, V.I. (1983) $O$ Estado $e \quad a$ Revolução. São Paulo: Hucitec.

Lungaretti, C. (2004). Náufrago da utopia. São Paulo: Geração Editorial. Michels, R. (1982) Sociologia dos Partidos Políticos. Brasília: Ed. UNB. 
Mir, L. (1994). A Revolução impossível: a esquerda e a luta armada no Brasil. São Paulo: Best Seller.

Pichon-Rivière, E. (1986). O processo grupal. São Paulo: Martins Fontes.

Reis Filho, D. A. (1990). A Revolução faltou ao encontro: os comunistas no Brasil. São Paulo: Brasiliense.

Reis Filho, D. A. \& Sá, J. F. (Orgs.)(2006). Imagens da revolução: documentos políticos das organizações clandestinas de esquerda dos anos 1961-1971. São Paulo: Expressão Popular, $2^{\mathrm{a}}$ ed.

Ridenti, M. (1993). O Fantasma da Revolução Brasileira. São Paulo: UNESP.

Salles, A.P. (coord.) (2008). A ditadura militar em Goiás: depoimentos para a História. Goiânia, GO: Poligráfica off-set e digital.
Vázquez, F. (1997). El dispositiu d'anàlisi de dades: 1'Anàlisi de contingut temàtic/categorial (Investigació i Coneixement Psicosocial). Mimeografado

Domenico Uhng Hur: Prof. Adjunto II do curso de Psicologia da Universidade Federal de Goiás. Psicólogo, mestre e doutor em Psicologia Social pelo Instituto de Psicologia da USP, com estágio doutoral na Universitat Autònoma de Barcelona/Catalunya. Membro do CRISE núcleo de estudos e pesquisas Crítica, Insurgência, Subjetividade e Emancipação. E-mail: domenicohur@hotmail.com 